\title{
NUMERICALPREDICTION OF AERODYNAMIC NOISE GENERATED FROM MISSILE FOR LOW MACH NUMBER FLOWS
}

\author{
Vladimir Jazarević, Boško Rašuo
}

Original scientific paper Paper describes numerical prediction of aerodynamic noise generated from the missile. Simulation of turbulent flow is done solving incompressible Navier-Stokes equation, where turbulence is modelled with the orthogonal subgrid scale (OSGS) method with dynamical subscales. Because of comparison, the same simulation is done using the LES (Large Eddy simulation). It is shown how simulation of turbulent flow affects the prediction of acoustic sources calculated using Lighthill's analogy. Translation from time to frequency domain is done through DFT (Direct Fourier Transform), which gives smaller usage of memory. Acoustic sources are used in inhomogeneous Helmholtz equation to simulate pressure wave propagation in the domain. It is shown that OSGS with dynamical subscales gives better representation of the spectrum. Overall, better prediction of energy transfer across large and small eddies will give better allocation and presentation of acoustics sources. These sources will change wave propagation of the pressure in acoustic field.

Keywords: aeroacoustics; direct Fourier transform; inhomogeneous Helmholtz equation; Litghill's analogy; noise; orthogonal SGS method with dynamical subscales

\section{Numeričko predviđanje aerodinamične buke koja se generira na projektilu pri malim Mahovim brojevima}

Izvorni znanstveni članak Rad predstavlja numeričko predviđanje aerodinamične buke koja se generira s projektila. Simulacija turbulentnog strujanja je urađena rješavanjem NavierStoksove jednadžbe za nestlačiv fluid, gde je turbulencija modelirana metodom orthogonalne podgrupne ljestvice (OSGS) s dinamičkim podljestvicama. Zbog usporedbe, ista simulacija je urađena i s metodom LES (Large Eddy Simulation). Pokazano je kako simulacija turbulentnog strujanja utječe na predviđanje akustičnih izvora koji su izračunati Lighthill analogijom. Translacija s vremenskog područja ka frekventnom području je urađena s DFT (Direct Fourier Transform), što dovodi do manje uporabe memorije. Akustični izvori su korišteni u nehomogenoj Helmholtz jednadžbi da bi se simuliralo širenje tlaka u područje. Pokazano je da ova metoda dovodi do bolje prezentacije spektra. Općenito, bolje predviđanje energetskog transfera između malih i velikih vrtloga dati će mogućnost bolje i snažnije prezentacije akustičnog izvora. Ovakvi izvori će promjeniti širenje vala u akustičnom polju.

Ključne riječi: aeroakustika; buka; direktna Furijeova transformacija; Litghill analogija; nehomogena Helmholtz jednadžba; ortogonalna SGS metoda s dinamičkim podljestvicama

\section{Introduction}

Over the last decades numerical analysis has become a very powerful tool for simulation of physical behaviour of the variety of systems. As it is known, Navier-Stokes partial differential equation describes the behaviour of fluid flow, but there are two problems that mathematicians have not been able to solve to the present day. The first one is uniqueness and smoothness of the solution of the Navier-Stokes equation. The equation is extremely difficult to solve in general and there are only few problems (very simple) which could be solved. Because of that, scientists and engineers have to deal with numerical algorithms that can produce an approximate solution. The second problem is turbulence, because fluid continually generates features at smaller and smaller scales eddies. Very roughly speaking, the existence and smoothness of Navier-Stokes equation is under question as well as how fast turbulent flow reaches smaller scale eddies properties. One of the most difficult challenges in numerical algorithms of turbulent flow is how to model these small scales eddies and their effect on large scales eddies. Also, how to properly define energy distribution between these small scales and large scales eddies. Turbulent flow around bodies that travel fast through the air makes fluctuations of pressure that our ear recognizes as sound.

It is this kind of physical phenomena that Aeroacoustics [1] deals with. With constant growth of capabilities of personal computers, a new field of computational mechanics has also emerged:
Computational Aeroacoustics (CAA) [2]. The aim of this field is to simulate and predict aerodynamically generated noise. The objective of this work is to present stabilized finite element method for the approximation of incompressible Navier-Stokes equation that models turbulent flow around missile ALAS and calculation of Lighthill's [3] tensor that arises in Aeroacoustics as acoustics sources generated from turbulent flow. These sources are the source for the inhomogeneous Helmholtz equation that calculates distribution of pressure field in order to predict sound in the domain.

This work shows how different methods of stabilization for the Navier-Stokes equation give different solution to the calculation of Lighthill's tensor and how this also affects pressure distribution in the domain. The natural way to predict turbulent flow is LES $[4 \div 6]$ which would be presented shortly. On the other side, there is another approach known as Variational multiscale method proposed by Hughes [7], which has different variations. Here, the orthogonal subgrid scale method with dynamic subscales proposed by the group of Ramon Codina [8] is considered. Calculation of acoustics sources and acoustic is done in the same domain as CFD domain. Here, CFD/CAA decomposition [9, 10] of domains is not followed as a goal to reduce memory usage. This is done through DFT (Direct Fourier Transform) incorporating the equation inside of the transient CFD loop. With the mentioned approach, domain decomposition and usage of FFT (Fast Fourier Transform) is avoided. Calculated aeroacoustic sources are on the right side of the inhomogeneous Helmholtz equation which is used to 
model the pressure wave propagation in the domain. Here, we are interested in small wave numbers $(k<15)$ avoiding the problems known as pollution error for large wave numbers, and because of that a simple Galerkin method is used to approximate acoustic behaviour. The goal is to show how small scales eddies have to be modelled and approximated as a function of large solvable scale and how they affect the simulation of turbulent flow and energy distribution. Also, it is shown how different turbulent flow modelling affects the calculation of acoustics sources and distribution of pressure waves in acoustic domain.

\section{Proposed methodology to simulate aerodynamic noise}

In order to simulate aerodynamic noise around missile ALAS shown in Fig. 1, the simulation will be divided into three main disciplines. The first one is the simulation of turbulent flow with CFD used to solve the incompressible Navier-Stokes equation. The assumption of incompressible flow is valid up to the Mach number 0,4 . Here, it is important to stress that it is chosen to simulate the missile in $2 \mathrm{D}$ ( $X Y$ plane and $Z X$ plane in Fig. 1 ). It is even known that flow around the missile is fully 3D.That decision is made in order to get a complex shape in 2D plane which can easily reproduce a wide turbulent flow and a lot of vortices but, on the other side, to reduce computer resources and time of simulation.

Numerical problem consists in solving partial differential equation in domain $\Omega \subset \mathbb{R}^{d}$ with the boundary condition $\Gamma=\partial \Omega$ and prescribed initial and boundary condition.

$$
\begin{aligned}
& \partial_{t} \boldsymbol{u}+\boldsymbol{u} \cdot \nabla \boldsymbol{u}-v \Delta \boldsymbol{u}+\nabla p=\boldsymbol{f} \text { in } \Omega, t>0 \\
& \nabla \cdot \boldsymbol{u}=0 \text { in } \Omega, t>0 \\
& \boldsymbol{u}(x, 0)=\boldsymbol{u}_{0}(x) \text { in } \Omega, t>0 \\
& \boldsymbol{u}(x, t)=\boldsymbol{u}_{D}(x, t) \text { on } \Gamma_{D}, t>0 \\
& \boldsymbol{n} \cdot \sigma(x, t)=\boldsymbol{t}_{N}(x, t) \text { on } \Gamma_{N}, t>0
\end{aligned}
$$

As it is known, the simulation of turbulent flow demands the appropriate design of numerical schemes (LES, Orthogonal SGS with dynamical subscales) in order to catch the physical behaviour of turbulence. The goal of turbulent flow simulation is to obtain the velocity vector $\boldsymbol{u}$ with exact fluctuations and productions of wakes.

The second part consists of calculating the acoustics sources using the method proposed by Lighthill, which means calculation of Reynolds tensor $\rho_{0}(\nabla \otimes \nabla):(\boldsymbol{u} \otimes \boldsymbol{u})$.

In order to keep the advantages of using $C^{0}-$ class finite elements, Reynolds tensor is expressed in the form

$\rho_{0}(\nabla \otimes \boldsymbol{u}):(\nabla \otimes \boldsymbol{u})^{\mathrm{T}}=s(x, t)$. After the source term in time domain is obtained, it has to be transformed to the frequency domain, using DFT.

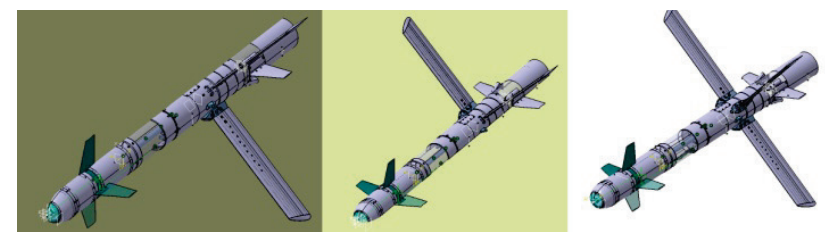

Figure 13-D model of Missile system ALAS with the XY and XZ planes for $2 \mathrm{D}$ computational domains
The third part consists of solving inhomogeneous Helmholtz equation using the source term obtained in the previous step in order to simulate pressure wave propagation in the domain, which is known as simulation of acoustic part. The same domain is used as in CFD part. Mathematical problem involves finding pressure $\mathrm{p}$ in domain $\Omega \subset \mathbb{R}^{d}$ with the boundary condition $\Gamma_{N} \cup \Gamma_{\infty}=\partial \Omega$.

$-\Delta p(x, \omega)+k_{0}^{2} p(x, \omega)=s(x, \omega)$ in $\Omega$

$\nabla p(x, \omega) \cdot n=0$ on $\Gamma_{N}$

$\nabla p(x, \omega) \cdot n=i k_{0} p$ on $\Gamma_{\infty}$

This is done applying the Galerkin method because we deal with a small wave number $\mathrm{k}_{0}$ which does not produce instabilities in numerical solution of Helmholtz equation known as dispersion problem. Fig. 2 shows graphical representation of the steps required to obtain aeroacoustics simulation.

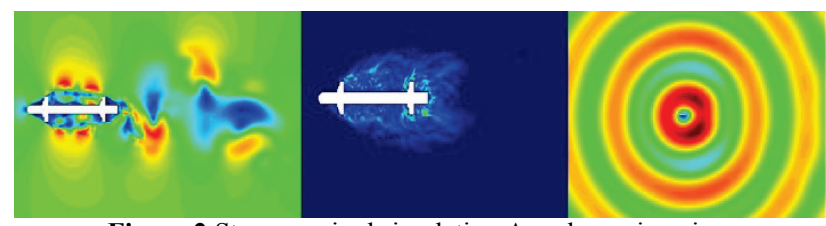

Figure 2 Steps required simulating Aerodynamic noise

\subsection{LES method for solving turbulent flow}

In order to simulate high Reynolds number turbulent flow, the choice has to be made between three usual approaches [11]. The first one is DNS (Direct Numerical Solution) which is not suitable for aeroacoustics simulation because of high computational cost in the area of high Reynolds numbers.

The second one RANS (Reynolds Averaged NavierStokes) cannot capture time fluctuations for proposed Reynolds numbers. The third method is LES (Large Eddy Simulation) which seems to be appropriate for the proposed problem [12].

The main idea behind LES is to decompose the velocity and pressure field at continuum level into large scales and small scales, where large scales could be captured from FEM mesh. Properly modelling small scales is crucial as well as their effects on large scales. The scale decomposition is done through a traditional method of the filtering process. After filtering, Eqs. $(1) \div(5)$ have the form:

$\partial_{t} \overline{\boldsymbol{u}}+\overline{\boldsymbol{u}} \cdot \nabla \overline{\mathbf{u}}-v \Delta \overline{\mathbf{u}}+\nabla \mathrm{p}=\boldsymbol{f}-\nabla \cdot \mathcal{R i n} \Omega x(0, T)$

$\nabla \cdot \overline{\boldsymbol{u}}=0$ in $\Omega x(0, T)$

$\overline{\boldsymbol{u}}(x, 0)=\overline{\boldsymbol{u}}_{0}(x)$, in $\Omega$

In Eq. (9) $\mathcal{R}=\overline{\boldsymbol{u} \otimes \boldsymbol{u}}-\overline{\boldsymbol{u}} \otimes \overline{\boldsymbol{u}}$ represents the residual stress tensor or sub grid scale tensor. Different modelling of residual stress tensor gives different methods of LES. Here, a famous Smagorinsky $[13,14]$ model is chosen for turbulent flow simulation. The idea to show the simulation of turbulent flow using the LES Smagorinsky model is to compare one of the most used methods with the proposed method of orthogonal SGS with dynamical subscales. 


\subsection{Orthogonal SGS method with dynamical subscales}

The idea behind SGS method is also to decompose the velocity and velocity test function on resolvable (capture with FEM mesh) or large scales and nonresolvable or small scales. The decomposition of $\boldsymbol{u}=$ $\boldsymbol{u}_{h}+\widetilde{\boldsymbol{u}}, \boldsymbol{v}=\boldsymbol{v}_{\boldsymbol{h}}+\widetilde{\boldsymbol{v}}$ refers to space splitting $V_{0}^{d}=V_{h, 0}^{d} \oplus$ $\tilde{V}_{h}^{d}$. The velocity time derivation can be split as $\partial_{t} \boldsymbol{u}=$ $\boldsymbol{\partial}_{\boldsymbol{t}} \boldsymbol{u}_{h}+\boldsymbol{\partial}_{\boldsymbol{t}} \tilde{\boldsymbol{u}}$ where the second term is saved because it is chosen to deal with dynamical subscales [15]. Enforcing the sub scales to be $\mathrm{L}^{2}$ orthogonal to the finite element or, in other words, $\tilde{V}_{0}$ is taken as subspace of $V_{h}^{\perp}$ this solution leads to the separate energy bounds for the two different scales. The separation of the scales is only proper if they are orthogonal in the sense that the total kinetic energy is the sum of the kinetic energy of $\boldsymbol{u}_{h}$ plus the kinetic energy of small scales. Also, the pressure and pressure test function are decomposed as $p=p_{h}+\tilde{p}$, $q=q_{h}+\tilde{q}$ corresponding to the space splitting $Q_{0}=$ $Q_{h, 0} \oplus Q_{0}$. In formulation the pressure subscales are not used. Applying the ideas in equations (1)-(5) it is formulated:

$$
\begin{aligned}
& \begin{aligned}
\begin{array}{l}
\left.\partial_{t} \boldsymbol{u}_{h}, \boldsymbol{v}_{h}\right)+\left(\boldsymbol{u}_{*} \cdot \nabla \boldsymbol{u}_{h}, \boldsymbol{v}_{h}\right)+v\left(\nabla \boldsymbol{u}_{h}, \nabla \boldsymbol{v}_{h}\right) \\
-\left(p_{h}, \nabla \cdot \boldsymbol{v}_{h}\right)+\left(q_{h}, \nabla \boldsymbol{u}_{h}\right)
\end{array} \\
+\left(\partial_{t} \widetilde{\boldsymbol{u}}, \boldsymbol{v}_{h}\right)-\sum_{K}\left\langle\widetilde{\boldsymbol{u}}, \boldsymbol{u}_{*} \cdot \nabla \boldsymbol{v}_{\boldsymbol{h}}+\vartheta \Delta \boldsymbol{u}_{h}+\nabla q_{h}\right\rangle_{k} \\
+\sum_{K}\left\langle\widetilde{\boldsymbol{u}}, \vartheta \boldsymbol{n} \cdot \nabla \boldsymbol{v}_{h}+q_{h} \boldsymbol{n}\right\rangle_{\partial K}=\left\langle\boldsymbol{f}, \boldsymbol{v}_{h}\right\rangle \\
\left(\partial_{t} \widetilde{\boldsymbol{u}}, \widetilde{\boldsymbol{v}}\right)+\sum_{K}\left\langle\boldsymbol{u}_{*} \cdot \nabla \widetilde{\boldsymbol{u}}-v \Delta \widetilde{\boldsymbol{u}}, \widetilde{\boldsymbol{v}}\right\rangle_{K}+\sum_{K}\langle v \boldsymbol{n} \cdot \nabla \widetilde{\boldsymbol{u}}, \widetilde{\boldsymbol{v}}\rangle+ \\
\sum_{K}\left\langle\partial_{t} \boldsymbol{u}_{h}+\boldsymbol{u}_{*} \nabla \boldsymbol{u}_{h}-v \Delta \boldsymbol{u}_{h}+\nabla p_{h}, \widetilde{\boldsymbol{v}}\right\rangle+\sum_{K}\left\langle v \boldsymbol{n} \cdot \nabla \boldsymbol{u}_{\boldsymbol{h}}-\right. \\
\left.p_{\boldsymbol{h}} \boldsymbol{n}, \widetilde{\boldsymbol{v}}\right\rangle_{\partial \boldsymbol{k}}=\langle\boldsymbol{f}, \widetilde{\boldsymbol{v}}\rangle
\end{aligned}
\end{aligned}
$$

Eq. (12) defines large scales and Eq. (13) defines small scales prior to assuming that subscales will be zero at the element boundaries. The first line in Eq. (12) is the same as for the Galerkin method. In the second line the first term defines the already defined stabilization methods as SUPG (Streamline Upwind Petrov Galerkin method), GLS (Galerkin Least Square) SGS (Subgrid Scale method) [16].

It is known that these methods stabilized convective term and give rise to equal interpolation for the velocity and pressure field. The second term in the second line of equation defines the dynamical subscales, where the third term defines the global momentum conservation not satisfied in the Galerkin approach, and the last term corresponds to Reynolds stress for subscales. The next goal is to find solution of small scales in Eq. (13) as a function of large scales and then to put back that result in Eq. (12). The equation could be written in a differential form:

$\delta_{t}+\left(\boldsymbol{u}_{h}+\tilde{\boldsymbol{u}}\right) \cdot \nabla \tilde{\boldsymbol{u}}-v \Delta \widetilde{\boldsymbol{u}}+\nabla \tilde{p}=r_{u, h}$

with $r_{u, h}$ representing residual of the finite element components $\boldsymbol{u}_{h}$ given by

$r_{u, h}=\mathrm{P}\left[\delta_{t} \tilde{\boldsymbol{u}}+\left(\boldsymbol{u}_{h}+\widetilde{\boldsymbol{u}}\right) \cdot \nabla \tilde{\boldsymbol{u}}-v \Delta \widetilde{\boldsymbol{u}}+\nabla \tilde{p}-\boldsymbol{f}\right]$ where $P=\mathcal{J}-\mathbb{P}_{h}$ stands for the $\mathrm{L}^{2}$ projection onto the appropriate velocity, or the pressure finite element space leads to the Orthogonal Subscale Stabilisation (OSS) approach. Using arguments based on a Fourier analysis for the subscale [17], the system of Eqs. (14) $\div(15)$ can be approximated as

$\partial_{t} \tilde{\boldsymbol{u}}+\frac{1}{\tau_{1}} \tilde{\boldsymbol{u}}=r_{u, h}$

where,

$\tau_{1}=\left(c_{1} \frac{v}{h^{2}}+c_{2} \frac{\left|\boldsymbol{u}_{h}+\widetilde{u}\right|}{h}\right)^{-1}$

where are: $c_{1}=4$ and $c_{2}=2$ - for linear triangular elements, $h$ - characteristic mesh element size.

The formulation of orthogonal sub grid scale with dynamical subscales can be formulated as

$\left(\partial_{t} \boldsymbol{u}_{h}, \boldsymbol{v}_{h}\right)+\left(\boldsymbol{u}_{*} \cdot \nabla \boldsymbol{u}_{h}, \boldsymbol{v}_{h}\right)+v\left(\nabla \boldsymbol{u}_{h}, \nabla \boldsymbol{v}_{h}\right)$ $-\left(p_{h}, \nabla \cdot \boldsymbol{v}_{h}\right)+\left(q_{h}, \nabla \boldsymbol{u}_{h}\right)+\sum_{K}\left\langle\widetilde{\boldsymbol{u}}, \boldsymbol{u}_{*} \cdot \nabla \boldsymbol{v}_{h}+v \Delta \boldsymbol{v}_{h}+\right.$

$\left.\nabla p_{h}\right\rangle_{\Omega_{e}}=\left(\boldsymbol{f}, \boldsymbol{v}_{h}\right)$

$\left(\partial_{t} \tilde{\boldsymbol{u}}, \widetilde{\boldsymbol{v}}\right)+\sum \tau_{K}^{-1}\langle\widetilde{\boldsymbol{u}}, \widetilde{\boldsymbol{v}}\rangle_{\Omega_{e}}+\sum\left\langle\boldsymbol{u}_{*} \cdot \nabla \boldsymbol{u}_{h}-v \Delta \boldsymbol{u}_{h}+\right.$ $\left.\nabla p_{h}, \widetilde{\boldsymbol{v}}\right\rangle=(\boldsymbol{f}, \widetilde{\boldsymbol{v}})$

\section{CFD simulation of turbulent flow over missile ALAS}

The first step in the simulation of aerodynamic noise is turbulence flow, with the goal to obtain velocity field in every time step as a purpose of calculation of acoustics sources [18].

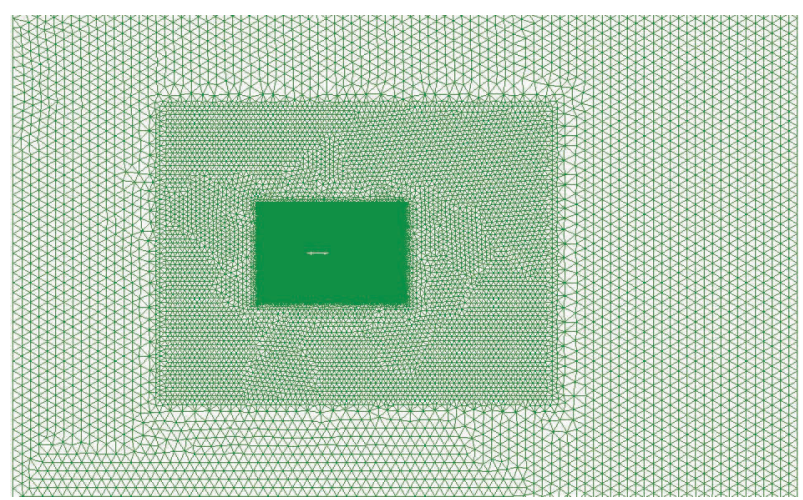

Figure 3 Mesh of the hall domain

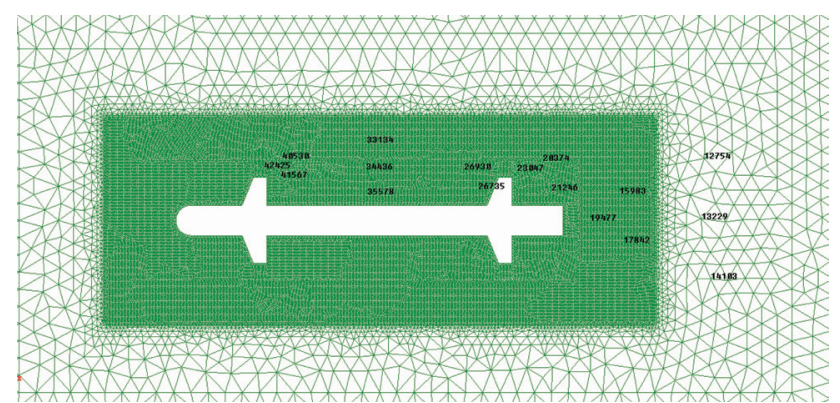

Figure 4 Mesh around 2D projection of missile in the $X Y$ plane

As it is known, the turbulent flow around missile is fully $3 \mathrm{D}$ and because of that if there is a need to recover the exact flow around a missile, there is a need for 3D simulation. Simulation of full $3 \mathrm{D}$ turbulent flow is very 
computationally expensive and time consuming. Because of that, the missile ALAS is projected onto the $Z X$ and $X Y$ plane, where the coordinate system is shown in Fig. 1. This 2D approximation has benefit from the viewpoint of a more complex turbulent flow with more wakes in a wide area around the missile. This is not exactly true in reality but from the viewpoint of comparing two approaches of modelling turbulent flow this approach gives much better visualisation of the comparison of aeroacoustic sources arising from fluctuations and gradient in the flow. The representation of mesh of hall domain is given in Fig. 3. It is obvious that the mesh around the missile is much finer (Fig. 4) to capture physical behaviour of the boundary layer and wakes, and starts to be coarser and coarser when it goes far from the missile.

Simulations are done as the rocket flies at cruising speed of $V=120 \mathrm{~m} / \mathrm{s}(M=0,35)$ and the angle of attack of the missile is 8 degrees. It is important to stress that both approaches are solved in totally the same domains and also with the same number of nodes and elements of the triangular mesh.

Numbers around the rocket in Fig. 4 represent the positions, where the velocity and pressure values fall in every time step. These are considered as sensors in flow, which makes the acquisition of velocity and pressure in time.

This is very useful because it is a direct indicator of difference between the two methods of modelling turbulent flow above proposed. The next figures show the velocity field around the missile in different time steps for both turbulent flow approaches. Figures are shown side by side for both approaches for the sake of simplicity, so as to compare both presentations.

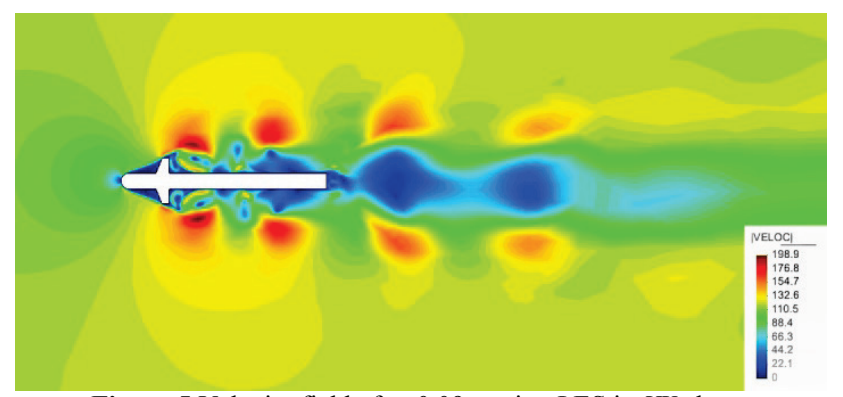

Figure 5 Velocity field after $0,09 \mathrm{~s}$ using LES in $X Y$ plane

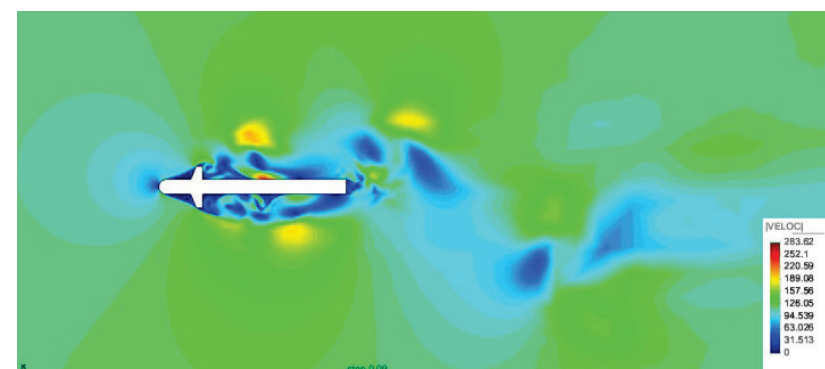

Figure 6 Velocity field after 0,09 s using DynOSS (Orthogonal Subgrid Scale method with dynamical subscales) in $X Y$ plane

It is noticeable from the figures that both approaches of modelling turbulent flow give different representation of the velocity field around the missile. Even with the same model, mesh and boundary conditions, the difference in turbulent pattern around the missile is noticeable. LES approach presents a fixed pattern of the behaviour of velocity giving more dissipative representation [19], capturing only large eddies and giving poor representation of small scales and their energy influence on large scales.

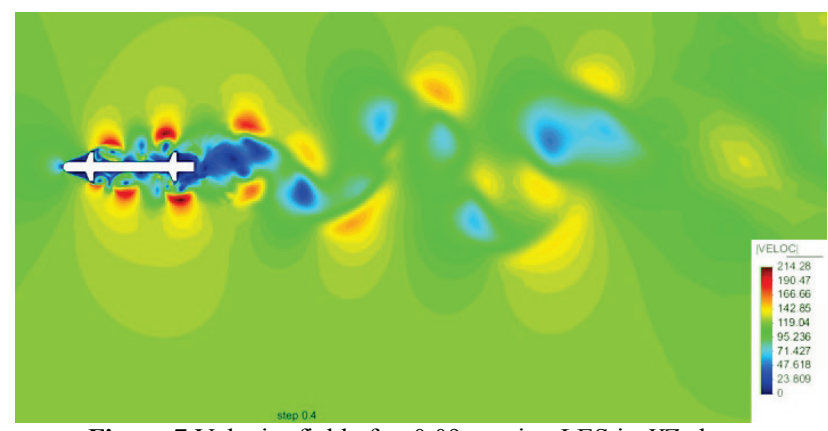

Figure 7 Velocity field after $0,09 \mathrm{~s}$ using LES in $X Z$ plane

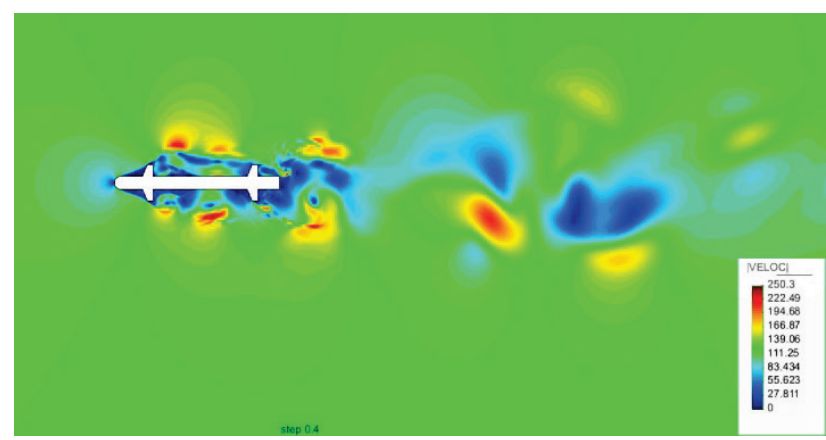

Figure 8 Velocity field after 0,09 s using DynOSS in $X Z$ plane

On the other hand, orthogonal SGS method with dynamical subscales has some features which give better presentation of turbulent flow. First, forcing $\mathrm{L}^{2}$ projection of small scales on the velocity finite element space leads to orthogonal subgrid scale which gives proper scale separation in the sense that total kinetic energy is the sum of kinetic energy of solvable (grid) scale plus kinetic energy of small (non - grid) scales [20].
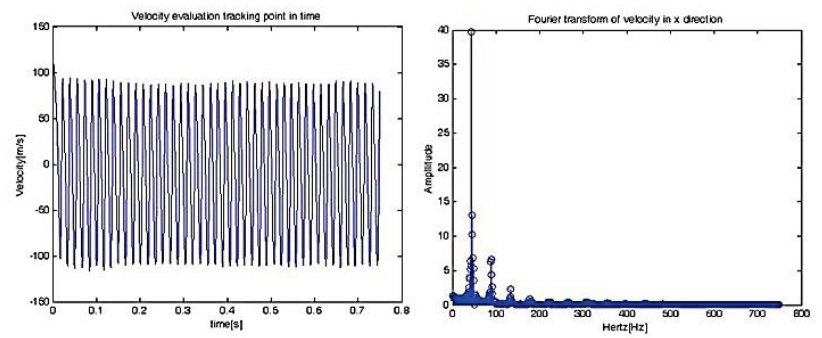

Figure 9 Time tracking in point in $X$ direction of velocity and spectral diagram using LES for turbulent modelling in $X Z$ plane
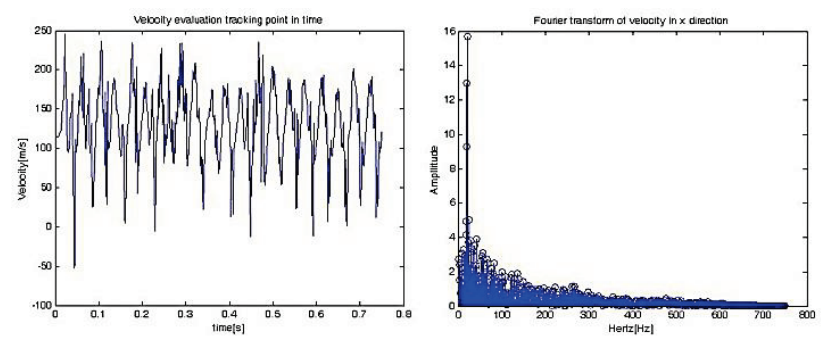

Figure 10 Time tracking in point in $\mathrm{X}$ direction of velocity and spectral diagram using DynOSS for turbulent modelling in $\mathrm{XZ}$ plane 
Second, modelling of dynamical subscales leads to correct behaviour of time discretization schemes and better accuracy.

On the other side, dynamical tracking of subscales gives the opportunity to model back scatter [21] that gives right energy transfer between the large and small scales.
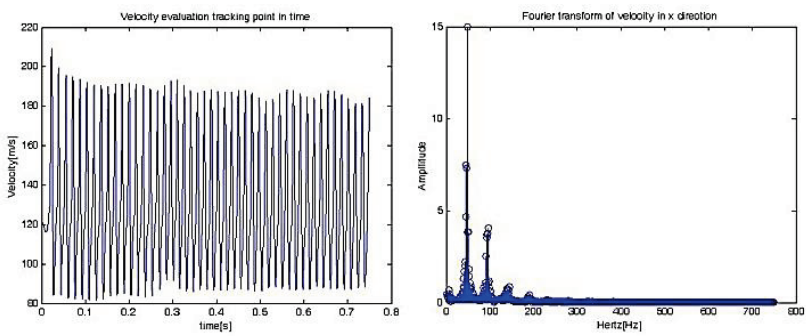

Figure 11Time tracking in point in $X$ direction of velocity and spectral diagram using LES for turbulent modelling in $X Y$ plane
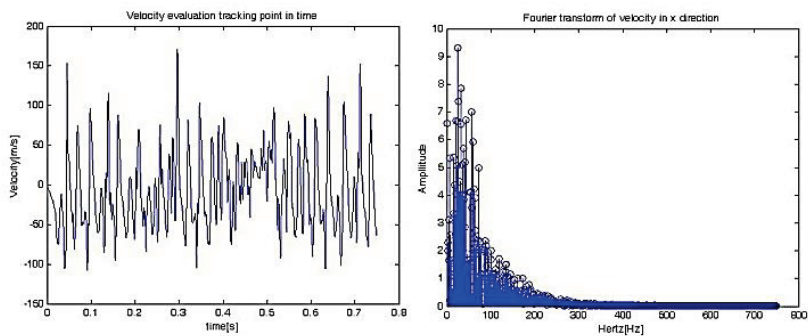

Figure 12Time tracking in point in $X$ direction of velocity and spectral diagram using DynOSS for turbulent modelling in $X Y$ plane
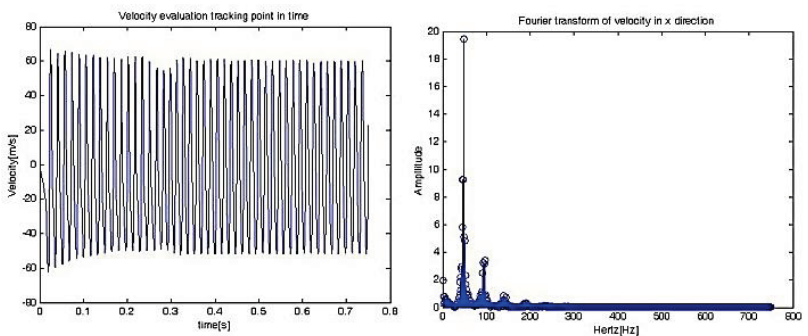

Figure 13 Time tracking in point in $Y$ direction of velocity and spectral diagram using LES for turbulent modelling in $X Y$ plane
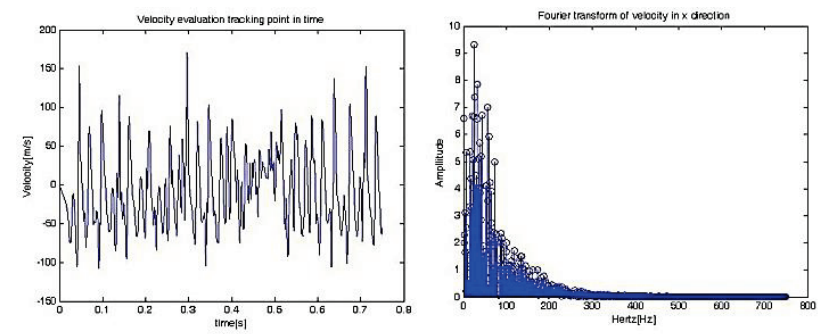

Figure 14 Time tracking in point in $Y$ direction of velocity and spectral diagram using DynOSS for turbulent modelling in $X Y$ plane

In Figs. 9, 11, 13 the dissipative structure of the LES approach is even more visible, giving poor spectral analysis. Recovering only large scales, giving good evidence this approach can capture turbulent characteristics to some point on the Komogorov scale diagram.

In Figs. 10, 12, 14 the Orthogonal SGS with dynamical subscale, on the other hand, recovers much richer spectral diagram, modelling both small and large scales and their energy interchange. It is important to highlight that representation in the figures is done for the same points shown in Fig. 4 for both methods. Spectral analysis in these figures gives rich representation, provides good evidence of recovering small scales and their influence on large scales.

\section{Calculation of aerodynamic noise sources}

For calculation of aerodynamic noise sources Lighthill's analogy [22] is used and thereafter DFT for transition from time domain to frequency domain. With regard to aerodynamic noise source computation, we have to compute [23]

$\rho_{0}(\nabla \otimes \nabla):(\boldsymbol{u} \otimes \boldsymbol{u})$

from the flow velocity vector $\boldsymbol{u}$ computed in CFD simulation mentioned above. After some tedious algebra and using incompressibility constraint we got an aerodynamic noise sources model

$\rho_{0}(\nabla \otimes \nabla):(\boldsymbol{u} \otimes \boldsymbol{u})=\rho_{0}(\nabla \otimes \boldsymbol{u}):(\nabla \otimes \boldsymbol{u})^{\mathrm{T}}=s(x, t)$

where we have implemented the $C^{0}$ Finite Element Method for the computation of the source model. After calculation of the source term, the time Fourier transform of source term in time domain has to be performed to pass to frequency domain. Using Fast Fourier Transform FFT $[24,25]$ for the source term transformation from time to frequency domain, it is necessary to store a large amount of instantaneous velocity fields. This requires a huge amount of computer memory resources.

To avoid this problem, the following strategy has been used. The frequencies at which the source term in frequency domain is wanted are chosen prior to starting the CFD computation.

During the evaluation of the CFD computation, the source term in time domain is automatically computed at each time step as well as its contribution to the source term in frequency domain.

At the end of the simulation, only the source term in frequency domain is retained, hence it is unnecessary to store acoustic source in time domain except for the steps at which visualization of the source term is desired. This has been done through the implementation of DFT [26] inside of the time loop of CFD calculation. The equation for implementation is as follows:

$$
\begin{aligned}
& H\left(f_{n}\right)=\int_{-\infty}^{\infty} h(t) e^{-2 \pi i f_{n} t} d t \approx \sum_{k=0}^{N-1} h_{k} e^{-2 \pi i f_{n} t_{k}} \Delta= \\
& \Delta \sum_{k=0}^{N-1} h_{k} e^{-2 \pi i k n / N}
\end{aligned}
$$

where are: $H\left(f_{n}\right)$ - function in frequency domain, $h(t)$ - function in time domain, $f_{n}$ - frequency instances, $t_{k}$ - time instances, $\Delta$ - time step between two times instances, $N$ - Number of points in domains, and $h_{k}$ value of function in time instances.

It is evident from all the figures that the proposed methodology of orthogonal SGS with dynamical subscales gives stronger and richer presentation of acoustic sources, giving smaller dipoles that come from small scales and their extra modelling. Good modelling of energy transfer in the flow between the large and small eddies recovers the fluctuating nature, which gives nice accent on gradients in the field around the missile. 


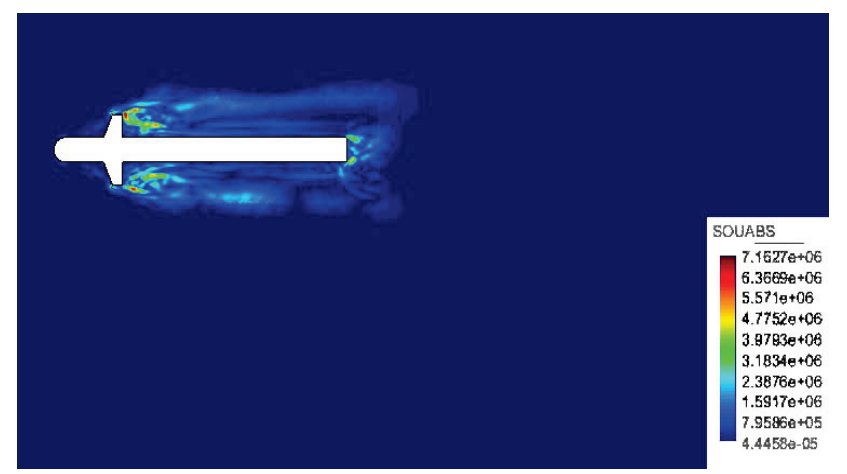

Figure 15 Absolute source field around missile, using LES approach in the $X Z$ plane

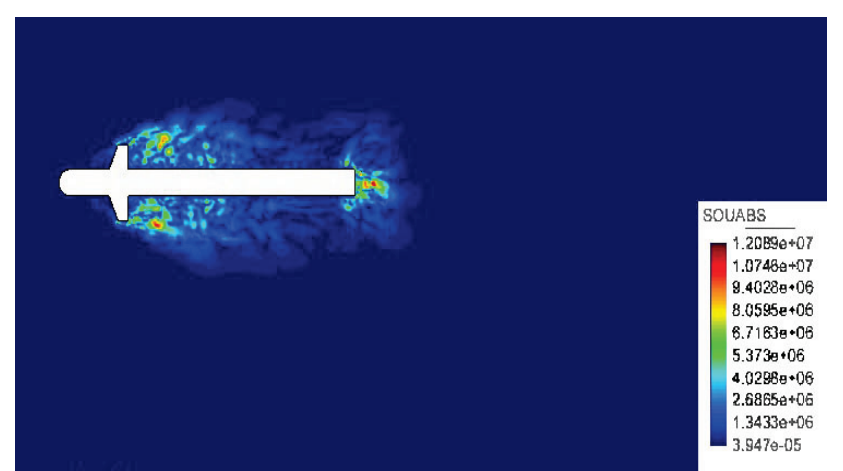

Figure 16 Absolute source field around missile, using DynOSS approach in the $X Z$ plane

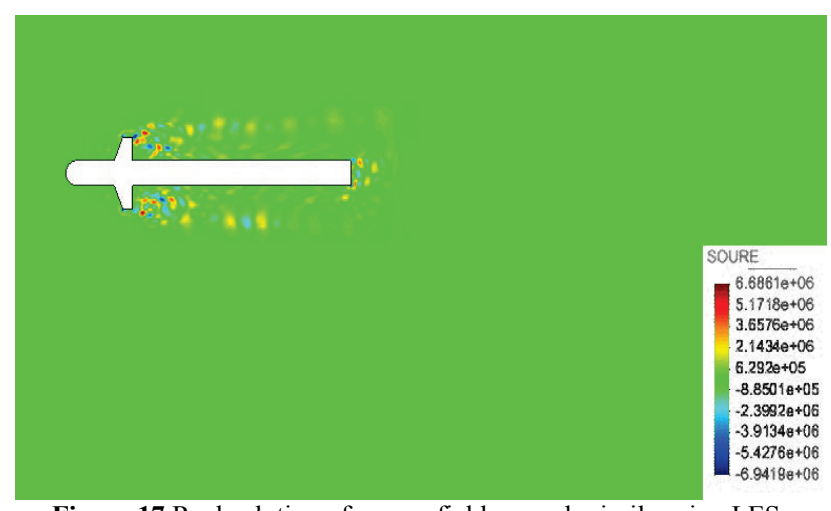

Figure 17 Real solution of source field around missile using LES approach in the $X Z$ plane

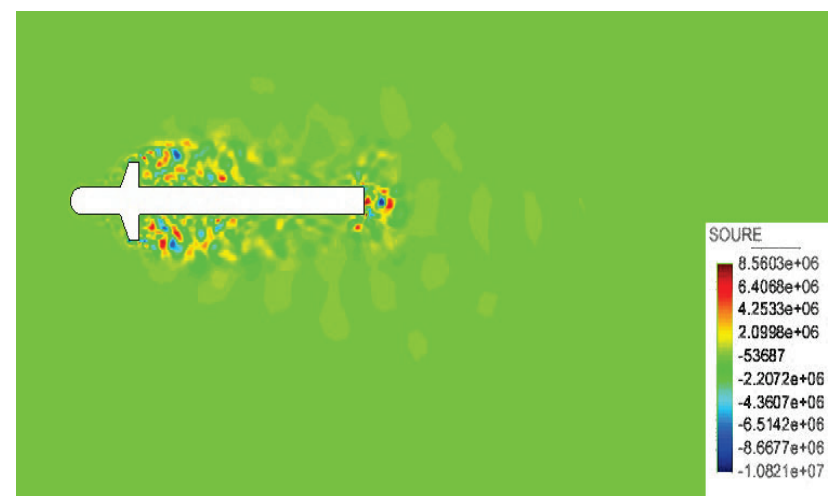

Figure 18 Real solution of source field around missile using DynOSS approach in the $X Z$ plane

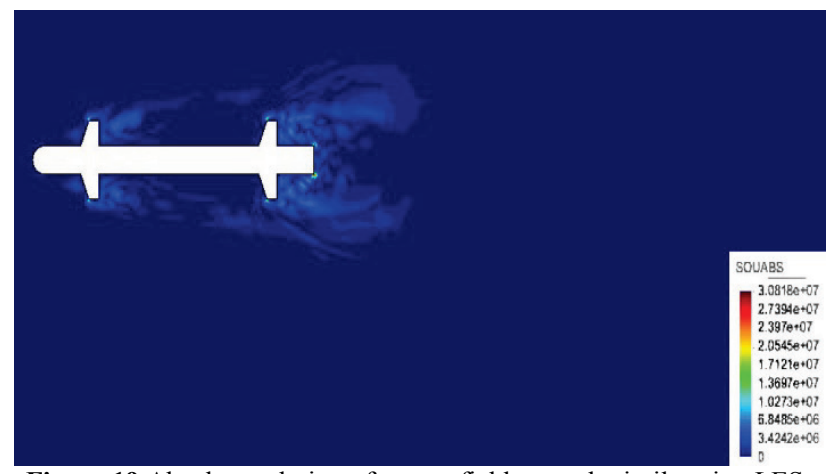

Figure 19 Absolute solution of source field around missile using LES approach in the $X Y$ plane

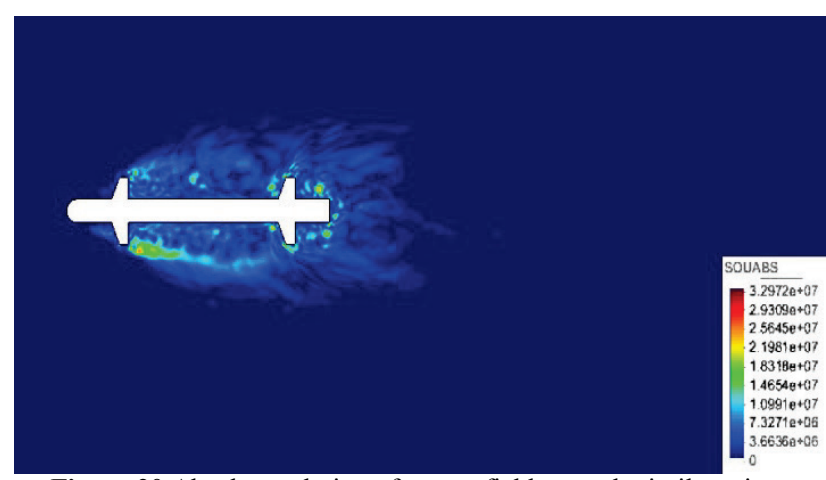

Figure 20 Absolute solution of source field around missile using DynOSS approach in the $X Y$ plane

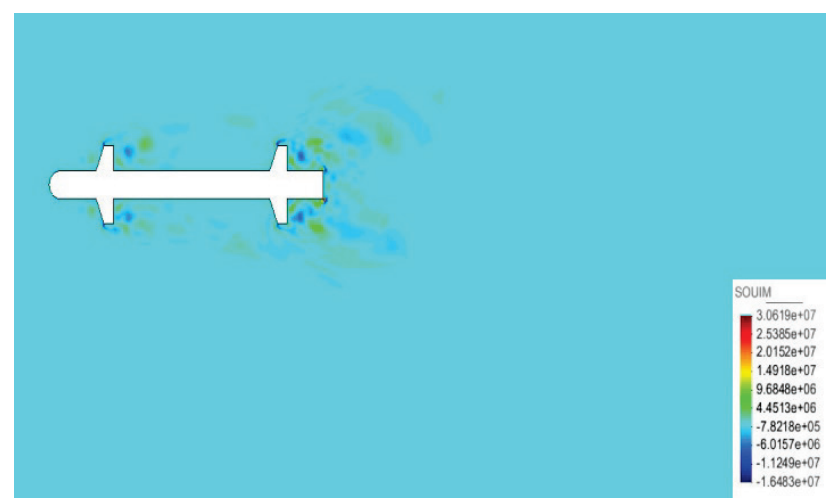

Figure 21 Imaginary solution of source field around missile using LES approach in the $X Y$ plane

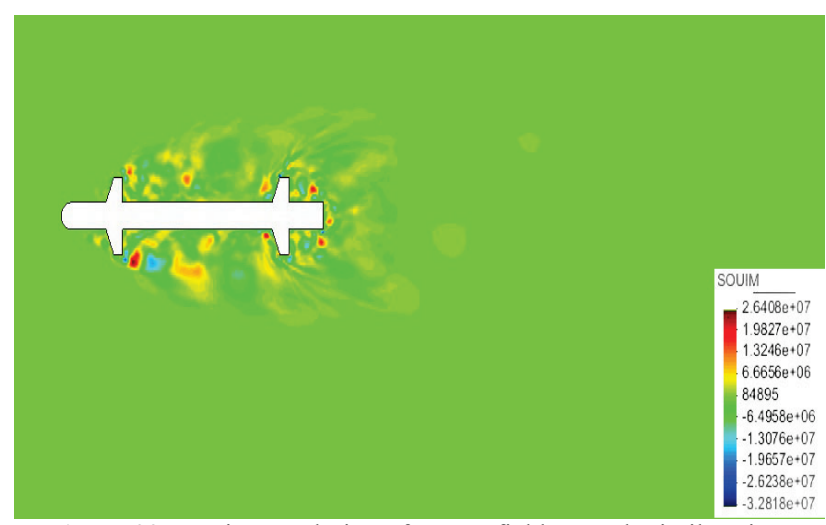

Figure 22 Imaginary solution of source field around missile using DynOSS approach in the $X Y$ plane

\section{Acoustic wave propagation}

In the third step of aerodynamic noise simulation it is needed to solve Inhomogeneous Helmholtz equation where the inhomogeneous part is already calculated in the 
previous step. The discrete weak form of the Galerkin method of Helmholtz equation stated in Eq. (6) is defined as $p_{h} \in Z_{h}$ such that:

$\left(\nabla p_{h}, \nabla v\right)-k^{2}\left(p_{h}, v\right)-i k\left\langle p_{h}, v\right\rangle_{\Gamma_{S}}=\left\langle s_{h}, v\right\rangle$

for all $v \in Z_{h}$,

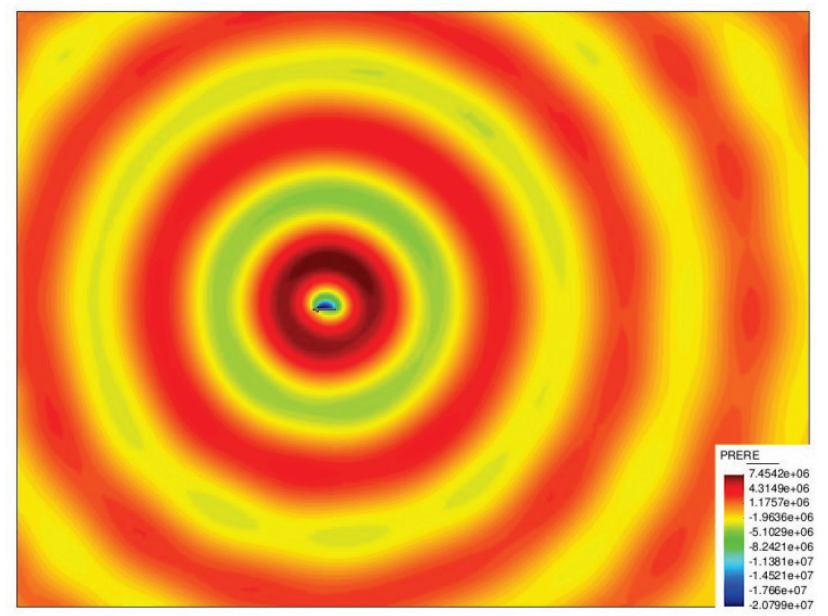

Figure 23 Real solution of pressure field for LES approach of turbulent flow

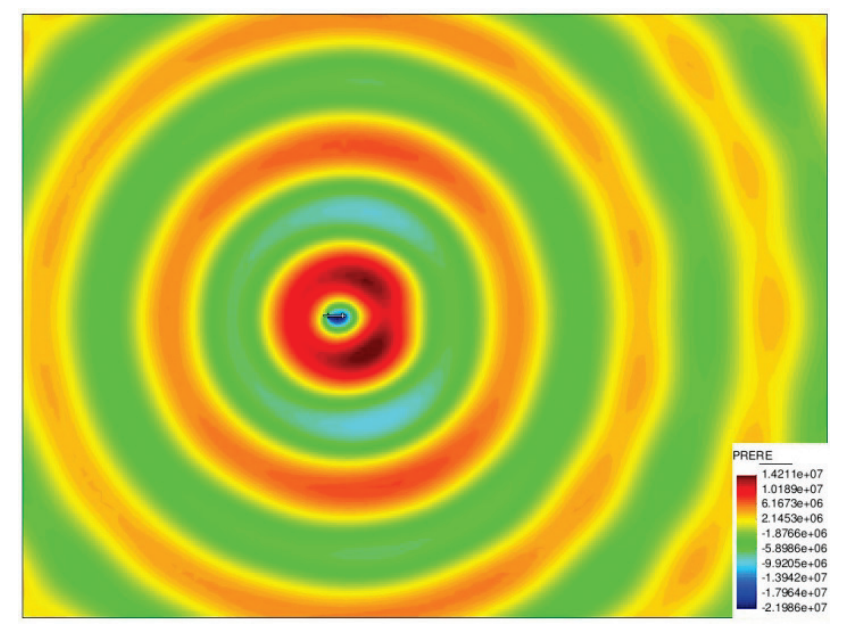

Figure 24 Real solution of pressure field for DynOSS approach of turbulent flow

Here, we are interested in small wave numbers $k=1,5$, in our case of presented figures, because large values produce stabilisation problems, known as pollution error [27]. Because of that, only by implementation of the Galerkin method will the dependencies of different modelling of turbulent flow on calculation of acoustic wave propagation be shown. It is important to mention that the domain of CFD is the same for Acoustic field and wave numbers are the same for all simulations, and only different is the source term that comes from different modelling of turbulent flow.

Better modelling of turbulent flow and richer approximation of acoustic sources also affect wave propagation of pressure and solution of inhomogeneous Helmholtz equation, as represented in Figs. 23 to 24 .

It is clear that Orthogonal SGS method with dynamical subscales gives stronger waves in the field.

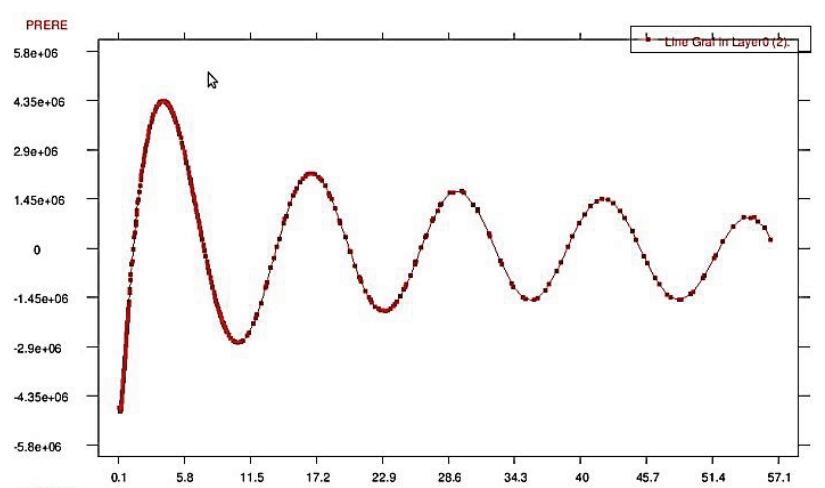

Figure 25 Pressure distribution in the cutting plane of Fig. 23

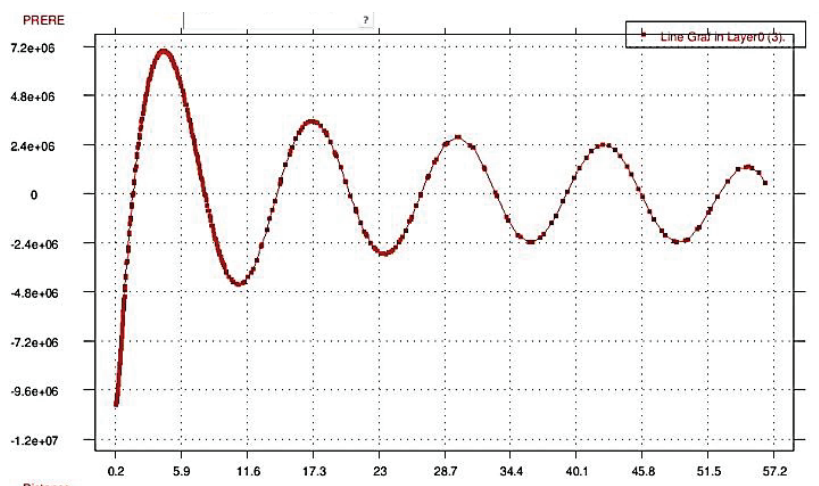

Figure 26 Pressure distribution in the cutting plane of Fig. 24

\section{Conclusion}

It is obvious that for the complex shape model in 2D of the missile method of Orthogonal SGS with dynamical scale the model of turbulent flow gives richer and stronger presentations of aeroacoustics sources, which leads to the same conclusion in propagation of acoustics waves in acoustic domain. The point to be highlighted is in a different approach of modelling small scales and their filtration in the solution of resolvable scale captured by the finite element mesh recovering good energy distribution in the area of small eddies.

Also, using dynamic subscales in the method gives the opportunity of modelling backscatter across large and small eddies giving energy flow across them. Also, the model is less dissipative as clearly shown in spectral diagrams showing the possibility to recover a wide range of frequencies arising from small scales and their energy somehow lost in the LES approach. Comparison of time tracking in the same point in the mesh for both methods is clearly distinctive between them and their modelling of turbulent flow. Modelling of turbulent flow is directly affecting Lighthill's tensor producing different results for both methods. It is clear that the proposed method recovers richer distribution of acoustic sources and also their strength. Different modelling of small eddies directly affects the distribution of dipoles in the near field of the missile.

Previously obtained results also affect inhomogeneous Helmholtz equation. Richer and stronger source term arising from the proposed method shows stronger waves pressure in the calculated domain. Also, the area near the rocket is clearly distinguished, where there is a concentration of acoustic sources. Everything stated nominates the proposed method as a good 
candidate for considering in the simulation of aeroacoustics phenomena in $2 \mathrm{D}$.

\section{References}

[1] Flowcs-Williams, J.; Hawkings, D. Sound generated by turbulence and surfaces in arbitrary motion. // Phil Trans Roy. Sec A, 264, (1969), pp. 321-342. DOl: 10.1098/rsta.1969.0031

[2] Hardin, J.; Hussaini, M. Computational Aeroacoustics, Springer-Verlag, 1993. DOI: 10.1007/978-1-4613-8342-0

[3] Lyrintzis, A. Review of Advances in Aeroacoustics (in Honor of Professor Geoffrey M. Lilley). // AIAA Journal. 49, 10(2011), pp. 2334-2335. DOI: 10.2514/1.J051010

[4] Canuto, V. Large Eddy simulation of turbulence: a subgrid scale model including shear, vortivity, rotation and buoyancy. // Astrophysical Journal. 428, (1994), pp. 729758. DOI: $10.1086 / 174281$

[5] Lesieur, M.; Metais, O.; Comte, P. Large Eddy Simulations In Turbulence, Cambridge University Press, 2005.

[6] Fuka, V.; Brechler, J. Implicit Large Eddy simulation of incompressible flow. // Hrvatski meterološki časopis. 43, 43/2(2008), pp. 667-669.

[7] Hughes, T. J. R. Multiscale phenomena: Green's function, the Dirichlet-to-Neumann formulation, subgrid scale models, bubbles and the origins of stabilized formula-tions. // Computer Methods in Applied Mechanics and Engineering. 127, (1995), pp. 387-401. DOI: 10.1016/0045-7825(95)00844-9

[8] Avila, M.; Codina, R.; Principe, J. Large eddy simulation of low Mach number flows using dynamic and orthogonal subgrid scales. // Computer and Fluids. 99, (2014), pp. 4466. DOI: 10.1108/HFF-07-2014-0238

[9] De Roeck, W.; Baelmans, M.; Desmet, W. Aerodynamic/Acoustic Splitting Technique for Computation Aeroacoustics Applications at Low-Mach Numbers. // AIAA Journal. 46, 2(2008), pp. 463-475. DOI: $10.2514 / 1.31953$

[10] Labbé, O.; Peyret, C.; Rahier, G.; Huet, M. A CFD/CAA coupling method applied to jet noise prediction. // Computer and Fluids. 86, (2013), pp. 1-13. DOI: 10.1016/j.compfluid.2013.07.013

[11] Pope, S. Turbulent flows, Cambridge University Press, 2000. DOI: $10.1017 / \mathrm{CBO} 0780511840531$

[12] Lai, L.; Djambazov, G. S.; Lai, C. H.; Pericleous, K. A. Comparison of Higher-Order Numerical Schemes and Several Filtering Methods Applied to Navier-Stokes Equations with Applications to Computational Aeroacoustics (CAA). // Computational Mechanics. (2009), p. 237. DOI: 10.1260/174830108788251746

[13] John, V. Large Eddy Simulation of Turbulent Incompressible Flows: Analytical and Numerical Results for a Class of Les Models, Springer Verlag, 2004. DOl: 10.1007/978-3-642-18682-0

[14] Liu, Y.; Tucker, P.; Kerr, R. Linear and nonlinear model large eddy simulation of plane jet. $/ / 44^{\text {th }}$ AIAA Aerospace Science meeting and exhibit, 9-12 January 2006. DOI: 10.1016/j.compfluid.2007.02.005

[15] Codina, R.; Principe, J.; Guasch, O.; Badia, S. Time dependent subscales in the stabilized finite element approximation of incompressible flow problems. // Computation Methods Applied. Mech. Eng. 196, (2007), pp. 2413-2430. DOI: 10.1016/j.cma.2007.01.002

[16] Ruperto, P.; Bonet, C. Numerical Stabilization of Convection-Diffusion-Reaction Problems. // March 2006.

[17] Codina, R. Stabilized finite element approximation of transient incompressible flows using orthogonal subscales. // Computer Methods in Applied Mechanics and Engineering. 191, (2002), pp. 4295-4321. DOI: 10.1016/j.apnum.2006.11.011

[18] Jazarević, V.; Rašuo, B. Computation of acoustic sources for the landing gear during the take-off and landing. // FME Transactions. 41, 3(2013), pp. 180-188.

[19] Principe, J.; Codina, R.; Henke, F. The dissipative structure of variational multiscale methods for incompressible flows. // Comput. Methods Appl. Mech. Eng. 199, (2010), pp. 791-801. DOI: 10.1016/j.cma.2008.09.007

[20] Guasch, O. Computational aeroacoustics and turbulance modelling of low speed flows using subgrid scale stabilised finite element methods PhD thesis, (2007), Universitat Politecnica de Catalunya

[21] Badia, S.; Codina, R.; Gutierrez-Santacreu, J. V. Longterm stability estimates and existence of a global attractor in a finite element approximation of a global attractor in a finite element approximation of the Navier-Stokes equations with numerical subgrid scale modelling. // SIAM J. Numer. Anal. 48, (2010), pp. 1013-1037. DOI: 10.1137/090766681

[22] Lighthill, M. J. On Sound Generated Aerodynamically. I. General Theory. // Proc. R. Soc. Lond. A, 211, (1952), pp. 564-587. DOI: 10.1098/rspa.1952.0060

[23] Lighthill, M. J. On Sound Generated Aerodynamically. II. Turbulence as a Source of Sound. // Proc. R. Soc. Lond. A, 222, (1954), pp. 1-32. DOI: 10.1098/rspa.1954.0049

[24] Duhamel, P.; Vetterli, M. Fast Fourier transforms: a tutorial review and a state of the art. // Signal Processing. 19, (1990), pp. 259-299. DOI: 10.1016/0165-1684(90)90158-U

[25] Duspara, M.; Sabo, K.; Stoić, A. Acoustic emission as tool wear monitoring. // Tehnički vjesnik. 21, 5(2014), pp. 1097-1102.

[26] Smith, J. Mathematics of the Discrete Fourier Transform// Stanford University, 2002.

[27] Ihlenburg, F.; Babuska, I. Solution of Helmholtz problems by knowledge-based FEM. // University of Texas, December 1996.

\section{Authors' addresses}

MSc. Vladimir Jazarević, PhD student

University of Belgrade, Marka Oreškovića 12, 11000 Belgrade, Serbia e-mail: vlada.jazarevic@gmail.com Tel. +381659831003

\section{Prof. Dr Boško Rašuo}

University of Belgrade, Faculty of Mechanical Engineering, Aeronautical Department,

Kraljice Marije 16, 11000 Belgrade, Serbia e-mail: brasuo@mas.bg.ac.rs Tel. +381113302261 